\title{
Pago por impactos en proyectos de densificación residencial intensiva del Área Metropolitana de Santiago: análisis crítico de los aportes al espacio público en la nueva legislación chilena
}

Magdalena Vicuña. Pontificia Universidad Católica de Chile, Santiago, Chile. Nicole Pumarino. Pontificia Universidad Católica de Chile, Santiago, Chile. Andrea Urbina. Pontificia Universidad Católica de Chile, Santiago, Chile.

RESUMEN | Este artículo expone y analiza la potencial contribución que en Chile hace la nueva Ley de Aportes al financiamiento e implementación de espacios públicos. El trabajo simula el porcentaje de aporte de operaciones privadas de densificación residencial intensiva en quince barrios del Área Metropolitana de Santiago. La mencionada ley constituye un marco para avanzar hacia un desarrollo urbano equilibrado mediante pagos por impactos proporcionales a la densidad. Sin embargo, los resultados demuestran que el porcentaje de aporte es insuficiente para concretar los planes comunales e intercomunales de inversiones. A su vez, su contribución final en cesión de suelo o en dinero responde a variables de localización o superficie predial, porque el avalúo fiscal y la superficie predial tienen mayor incidencia en el aporte que la densidad del edificio residencial. Se demuestra que, al calcular los aportes con la densidad de ocupación, se producen distorsiones respecto de la densidad planificada por los instrumentos de planificación territorial.

PALABRAS ClAVE | espacio público, planificación urbana, renovación urbana.

ABSTRACT | This article presents and analyzes the potential contribution of the new Law of Contributions to Public Space, to the financing and implementation of public spaces. This article simulates the contribution of private intensive residential densification operations in 15 neighborhoods of the Metropolitan Area of Santiago. The Law constitutes a framework for moving towards balanced urban development through payments for impacts proportional to density. However, the results show that the contribution percentage is insufficient to implement the communal and inter-communal investment plans. In turn, their final contribution in land or money transfer responds to location or lot characteristics because tax assessment and the lot area have greater impact than the density of the residential building, on the contribution to public space. It is shown that when calculating the contributions with the occupation density, distortions occur with respect to the density planned by local zoning instruments.

KEYWORDs | public space, urban planning, urban renewal. 


\section{Introducción}

La densificación residencial es una de las principales tendencias del crecimiento urbano contemporáneo, especialmente en las principales ciudades de economías emergentes de Asia y Latinoamérica (Cho, Trivic, \& Nasution, 2017; De Mattos, Fuentes, \& Link, 2014; Hipólito de Oliveira et al., 2015). Una de las claves asociada a los procesos de densificación es la provisión equilibrada de espacios público de calidad que promuevan la peatonalidad y la proximidad de personas y actividades, lo que implica importantes niveles de inversión en bienes públicos urbanos. Sin embargo, muchas de estas ciudades evidencian formas de densificación y sobredensificación que generan impactos negativos, tales como congestión y degradación de la habitabilidad urbana (Angel, Parent, Civco, \& Bkei, 2011; Echenique, 2006; Fernández Per \& Arpa, 2007).

Desde la década de 1990, el Área Metropolitana de Santiago de Chile (AMS) evidencia procesos de densificación con distintos grados de intensidad, escalas e impacto (Vicuńa, 2017). En comunas como Estación Central y Santiago, las densidades brutas de los edificios residenciales pueden alcanzar hasta 15.000 hab/ha $10.000 \mathrm{hab} / \mathrm{ha}$, respectivamente. Estas hiperdensidades son posibilitadas por la ausencia de normas urbanísticas, permisividad ampliamente rentabilizada por el sector inmobiliario. En efecto, algunas comunas presentan importantes velocidade de retorno para estrategias del capital financiero, apoyadas por la inversión en infraestructuras, servicios y equipamientos (Hidalgo \& Arenas, 2009; López, 2015).

Por otro lado, los edificios de densificación residencial no mitigan los impactos generados por la mayor carga de personas, vehículos y volumen construido. Un 5\% de dichos edificios realiza un Estudio de Impacto al Sistema de Transporte Urbano (EISTU), mecanismo que solo considera el impacto en la vialidad y que, a pesar de abordar una materia que requiere una aproximación sistémica, es tratada caso a caso (Mensaje Presidencial a la Cámara de Diputados 90-360, 2012). Por otro lado, se ha evitado su aplicación mediante la definición de etapas de los proyectos.

En Chile, los impuestos territoriales (contribuciones) no alcanzan para financiar cabalmente la provisión de equipamientos y espacios públicos. Las contribuciones se establecen según el avalúo fiscal de la propiedad y su destinación va directamente a los municipios del país, no contándose con una asignación específica de inversión pública. Asimismo, solo un $20 \%$ de los departamentos en Chile paga contribuciones, dado que un $77 \%$ de las propiedades está exenta de pagar este impuesto (Razmilic, 2018).

Consecuentemente, a diferencia de otros países que cuentan con mecanismos para la participación del sector privado en el financiamiento de bienes público urbanos, en Chile la intensificación del uso de suelo no ha ido acompañada de exigencias dirigidas a los desarrolladores en materia de aportes en provisión de nuevos espacios públicos o mejoramiento de los existentes. En efecto, el único mecanismo disponible es cesión gratuita de suelo para espacio público, el cual se implementa exclusivamente en urbanizaciones para la extensión urbana mediante a exigencia de superficie para circulaciones, áreas verdes y equipamientos. Dicha superficie es proporcional a la densidad de la urbanización y tiene un límite máximo correspondiente al $44 \%$ de la superficie total de la urbanización.

Como respuesta a tal vacío en la gestión urbana, en el año 2016 se aprobó la Ley de Aportes al Espacio Público (Laep, Ley 20.958, Diario Oficial 15 octubre 2016), la cual tiene como principal objetivo que los proyectos de densificación aporten al espacio público y mitiguen los impactos sobre la movilidad urbana. La LAEP busca que todo nuevo proyecto colabore en la "conformación de ciudades equilibradas, en las cuales no solo los recintos privados sean los adecuados, sino también lo espacios públicos, los lugares donde transcurre gran parte de la vida de las personas" (Mensaje Presidencial a la Cámara de Diputados 90-360, 2012).

El presente artículo tiene por objetivo contribuir con una visión crítica de este nuevo mecanismo, a través del análisis de los aportes al espacio público derivados de la aplicación de la LAEP en edificios de densificación residencial del AMS. Se busca discutir en qué medida el aporte generado por los edificios de densificación residencial intensiva (más de cinco pisos) tiene el potencial de colaborar en la cantidad y calidad del espacio público del contexto urbano en el cual se emplazan.

\section{La Ley de Aportes al Espacio Público (LAep)}

La LAEP busca sostener el principio original de la legislación urbanística chilena (1931), que enfatiza que todo nuevo proyecto debe contribuir a la construcción de ciudad mediante la cesión gratuita de suelo para espacio público. La LAEP plantea que los proyectos de densificación deben contribuir en forma proporcional a su densidad y mediante dos mecanismos:

a. Mitigaciones definidas en Informes de Mitigación de Impacto Vial (Imiv) (que reemplazan los eISTU): consideran transporte público, privado y modos no motorizados, y se proponen en función del impacto sobre el sistema de movilidad local según los flujos de vehículos y peatones generados. Las mitigaciones se gestionarán a través de una plataforma electrónica -que reemplazará la actual ventanilla única de los EISTU- en la cual se ingresarán los principales datos del proyecto. La plataforma definirá el área de influencia del edificio y determinará la categoría de informe que se debe realizar (informe básico, intermedio o mayor). El Reglamento para la producción de los informes de mitigación ha sido elaborado por el Ministerio de Transporte y Telecomunicaciones. La LAEP entrará en vigencia 18 meses después de la publicación oficial de dicho Reglamento, ${ }^{1}$ esto es, en noviembre de 2020

b. Aportes al espacio público, que pueden entregarse en forma de cesión gratuita de suelo o en dinero equivalente al costo de la cesión según el avalúo fiscal del terreno. Los aportes que se realicen en dinero serán destinados a la ejecución de un Plan Comunal de Inversiones en Infraestructura y Espacio Público, administrado por cada municipio, y que contemplará proyectos, obras y medidas incluidas en los instrumentos de planificación territorial, priorizando

El Reglamento sobre mitigación de impactos al sistema de movilidad local derivados de proyectos de crecimiento urbano, se publicó en el Diario Oficial el 17 de mayo de 2019. 
condiciones de conectividad, accesibilidad, operación y movilidad. Las ciudades conformadas por más de una comuna contarán con un Plan Intercomunal de Inversiones en Infraestructura y Espacio Público, elaborado por las secretaría ministeriales regionales de Transporte y Telecomunicaciones, y de Vivienda y Urbanismo. Al menos un $40 \%$ de lo recaudado anualmente por cada municipio deberá destinarse a la ejecución de obras incluidas en el plan intercomunal. El $60 \%$ será destinado a obras comunales, de las cuales el $70 \%$ será invertido en movilidad.

Ambos mecanismos están regidos por tres principios: i) universalidad, referida a que todos los proyectos deben mitigar los impactos en la movilidad urbana y aportar al espacio público; ii) proporcionalidad, que indica que las mitigaciones deberán ser equivalentes a las externalidades, y los aportes a la densidad del proyecto; iii) predictibilidad, que establece que las mitigaciones se calcularán objetivamente mediante procedimientos estandarizados.

Los aportes se calcularán sobre la base de las fórmulas incorporadas a la Ordenanza General de Urbanismo y Construcciones (tabla 1), la cual establece un máximo de $44 \%$ de aporte para los edificios de hasta 8000 hab/ha. Los edificios que superan esta densidad mantienen dicho máximo, el cual se iguala al aporte máximo exigido a las urbanizaciones en extensión. De esta manera, la LAEP establece el cumplimiento sustitutivo de un requerimiento ya existente en la Ley General de Urbanismo y Construcciones (LGUC) en su artículo 70.

El cálculo de los aportes se basa en una densidad denominada "densidad de ocupación”, la cual a su vez está basada en la carga de ocupación de cada edificio La carga de ocupación tiene relación con el número de personas por superficie construida y varía según el destino de la edificación. Por su parte, la "densidad bruta" se refiere al número de viviendas según la superficie de terreno; esta superficie considera el predio más la superficie correspondiente hasta el eje del espacio público que enfrenta el predio. Esta última densidad es la que se utiliza en la planificación territorial y en el cálculo de las cesiones de terreno para urbanizaciones, y solo aplica para los proyectos habitacionales.

\begin{tabular}{|l|c|}
\hline \multicolumn{2}{|c|}{ Fórmulas UTILIZADAS PARA OBTENER EL PORCENTAJE DE APORTE } \\
\hline $\begin{array}{l}\text { Porcentaje de aporte al } \\
\text { espacio público (hasta 44\%) }\end{array}$ & $\frac{\%=\text { Densidad de ocupación x 11 }}{2000}$ \\
\hline Densidad de ocupación & $\frac{\text { Carga de ocupación x 10.000 }}{\text { Superficie de terreno }}$ \\
\hline Carga de ocupación & Superficie útil del proyecto \\
\hline $\begin{array}{c}15,20 \text { o } 30 \\
\text { (dependiendo de superficie promedio de los departamentos) }\end{array}$ \\
\hline
\end{tabular}

TABLA I | Fórmulas utilizadas para obtener el porcentaje de aporte

FUENTE: ELABORACIÓN PROPIA CON BASE EN ORDENANZA GENERAL DE URBANISMO Y CONSTRUCCIONHS
Los aportes pueden realizarse en cesión de suelo o en dinero. En el primer caso, se multiplica el porcentaje de aporte por la superficie del terreno y se obtiene la superficie por ceder. En el segundo, se multiplica la superficie resultante del cálculo anterior por el valor del avalúo fiscal vigente.

Se ha señalado que la LAEP contribuirá a un desarrollo urbano más sustentable y que fortalecerá la planificación y gestión urbana mediante la colaboración públicoprivada. El sector privado valora la certeza que tendrán los aportes; y los municipios, su universalidad. Asimismo, se valora que contemple recursos para obras no viales y su función redistributiva, al considerar que ciertas comunas pueden acumular mayores aportes que pueden invertirse en comunas deficitarias.

Desde otra perspectiva, se ha señalado que la LAEP corresponde a un impuesto territorial adicional, que puede replicar los problemas de los EISTU. El sector inmobiliario valora los aportes al espacio público, no así las mitigaciones, las cuales sí son valoradas por los municipios. Dicho sector critica que, al separar aporte y mitigación, se está cobrando dos veces el impacto del edificio. También se critica la no obligatoriedad de destinar los aportes al barrio donde se emplaza el edificio, de manera que la densificación constituya un proceso de transformación positivo de su entorno.

Respecto de las mitigaciones, se critica la poca certeza existente respecto de cómo se calcularán e implementarán, así como la complejidad que ello implicará para los municipios, especialmente cuando las medidas no sean ejecutadas por el privado. Se argumenta que perjudicarán a los proyectos inmobiliarios pequeños y medianos. Además, se ha objetado la falta de involucramiento de los municipios en el proceso de elaboración de la ley y se la ha catalogado como un "triunfo de los transportistas".

Estos aspectos llevaron a que la ley fuera discutida por más de seis años, proceso que no estuvo exento de controversia y debate. En su tercer trámite constitucional en la Cámara de Diputados, el año 2013, se realizó una indicación sustitutiva que generó cambios sustanciales y que responde al cambio de gobierno. En esta discusión subyace un principio fundamental para la planificación urbana, como es la función social de la propiedad inmueble, y plantea la interrogante respecto de hasta dónde y cuánto el privado debe hacerse cargo de los impactos que genera y cuánto corresponde a cada quien la responsabilidad de construir ciudad. También releva la importancia de contar con mecanismos complementarios a los instrumentos de planificación urbana, los cuales tienden a ser más reactivos que propositivos frente a transformaciones urbanas tan dinámicas como lo ha sido la densificación residencial durante las últimas tres décadas.

\section{Propiedad privada, derechos y deberes en la coproducción de ciudad}

Función social de la propiedad del suelo urbano

a provisión de espacios públicos de calidad y en proporción con las nuevas densidades es fundamental para alcanzar procesos de densificación sustentables (Ewing \& Cervero, 2010; Gehl, 2010; Pont \& Haupt, 2009; entre otros). Ante la creciente escasez de recursos por parte de gobiernos centrales y locales, surgen mecanismo de asociatividad público-privada para la inversión en espacios públicos. Pagos por 
impacto, impuestos a la propiedad, contribuciones e instrumentos de captación de plusvalías, constituyen un repertorio de mecanismos para financiar o complementa la inversión pública en bienes urbanos.

En efecto, la propiedad del suelo urbano, aunque privada, tiene una función social. Este principio fundamental, introducido en 1919 por la Constitución de Weigmar (Cordero, 2008b), otorga al Estado la potestad de imponer limitaciones al dominio privado en pro del bien común, mientras respete las garantías constitucionales (Cabrera, 2008; Rajevic, 2000). La función social de la propiedad es uno de los problemas centrales de la planificación urbana (Krueckeberg, 1995), la cual busca mediar el conflicto entre los intereses privados, que buscan maximizar el aprovechamiento de la propiedad, y los públicos, que buscan cautelar fines y objetivos colectivos (Cordero, 2008a).

Así, distintos regímenes de propiedad otorgan diversos grados de intervención sobre la propiedad del suelo. Estados Unidos, en su carta fundamental, incorpora el Police Power, que otorga a los municipios la potestad para dictar cambios normativos, siempre que promuevan el bienestar general (Mancuso, 1980). América Latina tiene en su legislación civil una marcada tendencia a la consagración de la propiedad regulada, considerando el principio de la supremacía del bien común sobre el privado (Cabrera, 2008). La Constitución Política de Chile habilita a legislador para configurar distintos regímenes de propiedad, al determinar como contenido intrínseco de cada una de ellas su respectiva función social (Cordero, 2008a).

Los límites de altura, densidad, expropiaciones, deberes de cesión gratuita de suelo y límites urbanos, entre otras normas urbanísticas, así como los requerimientos de pagos por impactos, contribuciones e impuestos territoriales, buscan sustrae poderes sobre el dominio privado para atribuírselos a los poderes públicos (Rajevic, 2000). Consecuentemente, los deberes y derechos asociados a la función social de la propiedad y consignados en instrumentos de planificación y gestión urbana, se encuentran en el centro de un debate político y económico (Krueckeberg, 1995).

\section{Restricciones al dominio privado y mecanismos de financiamiento para la} renovación de la ciudad existente

Crecientemente, la gestión urbana requiere de mecanismos que impliquen la participación del sector privado en el financiamiento urbano. Diversos países han desarrollado mecanismos que complementan los tradicionales instrumentos de planificación para la expansión y renovación urbanas (Sandroni, 2011; Smolka \& Furtado, 2001). Entre estos, destacan los mecanismos de captación de plusvalías, y los aportes urbanísticos o pagos por impactos. $Y$ aunque se diferencian en términos de objetivos, aplicación y modalidad de recaudación, comparten el propósito de cautelar equilibrios entre el derecho de propiedad y el bien común.

Los mecanismos de captación de plusvalías buscan que las utilidades en el aumento de valor de suelo sean compartidas entre propietarios y comunidad (Rajevic, 2000) Conceptualmente, todos los mecanismos que exigen aportes de los propietarios corresponden a mecanismos de captación de plusvalías. Smolka y Amborski (2003) plantean que, aunque no están directamente asociados a una intervención pública en particular, los impuestos sobre el valor de suelo corresponden a una forma de recuperación de plusvalías, porque "el valor de la tierra está formado por los incrementos acumulados en el valor de ella" (p. 57). En este sentido, los mecanismos de aportes urbanísticos y pagos por impactos corresponden, en mayor o menor medida, a fórmulas de captación de plusvalías.

Así lo concibe la Ley de Suelo española, que establece el principio fundamental de "la participación de la comunidad en las plusvalías generadas por la acción de los entes públicos" (Doménech, 2014). Dado que los propietarios patrimonializan el derecho a edificar atribuido por las normas urbanísticas (Cordero, 2008a), estos mecanismos se aplican sobre el fundamento de que las acciones públicas pueden generar plusvalías significativas en la propiedad privada. Cuando por resultados externos a la propiedad inmueble (inversión pública, cambios normativos), esta aumenta significativamente de valor, la captación de plusvalías permite transferir dichas ganancias a la comunidad, transferencia amparada en la función social de la propiedad (Furtado, 1997; Rajevic, 2000; Smolka, 2013; Smolka \& Furtado, 2001).

La captación de plusvalías no ha sido ampliamente aplicada, y se la critica sobre la base de que las plusvalías pertenecen exclusivamente al propietario y solo es exigible al privado un mínimo de aportes para la nueva urbanización. En muchos países, Chile entre ellos, el derecho de propiedad se ha impuesto por sobre la función social de la propiedad (Clichevsky, 2001; Furtado, 1997). Aunque la captación de plusvalías implica una nueva manera de abordar la gestión urbana, que "desplaza la centralidad que históricamente ha tenido el derecho individual de propiedad del suelo en la política urbana latinoamericana" (Cuenya \& González, 2017, p. 3), la tendencia a incorporarla en la política urbana es creciente (Smolka \& Furtado, 2001).

En cuanto a los aportes urbanísticos y pago por impactos, ellos cobraron relevancia durante la década de los setenta en Estados Unidos y Europa, producto de la contracción presupuestaria de los gobiernos locales (Nelson, 2007). En América Latina también constituyen uno de los mecanismos más recurrentes (Smolka, 2003) través de los cuales las administraciones obtienen aportes privados para el financiamiento de costos e impactos asociados a nuevas infraestructuras y espacios públicos (Sánchez de Madariaga, 1997)

Según Smolka y Amborski (2003), los aportes se fundamentan en dos principios: i) la mayor intensidad de edificación y de usos de suelo requiere mayor inversión en obras de infraestructura y servicios; y ii) la superficie edificada adicional es considerada un patrimonio público que no puede otorgarse a algunos ciudadanos en detrimento de otros, a menos que se compense a la sociedad por obtenerlos.

Por lo general, el pago está previamente definido mediante una fórmula, es proporcional a la carga del proyecto y se ejecuta una sola vez con la obtención del permiso de edificación o urbanización. Su aplicación ha transitado desde la eliminación de "barreras físicas al desarrollo urbanístico", la mitigación de externalidades negativas, y la provisión de beneficios sociales (Cámara de Diputados, Comisión de Vivienda, 2013 
Los Tax Incremental Fees (Estados Unidos) utilizan las futuras ganancias de impuestos para financiar los proyectos de mejoramiento urbano que promoverán dichas ganancias. Cuando una inversión pública aumenta el valor de suelo y desencadena nuevos desarrollos inmobiliarios, tanto el incremento de valor como la nueva inversión implican un aumento del valor afecto a impuesto territorial. Este aumento o Tax Increment es utilizado para financiar la deuda contraída para la inversión, principalmente en zonas con déficit de equipamientos e infraestructuras, donde el desarrollo no ocurriría por sí solo (Healey \& McCormick, 1999). Diverso estados han promulgado State Impact Fees Enabling Acts, legislaciones que habilitan a los gobiernos locales a cobrar por impactos (Mullen, 2015). Actualmente es un mecanismo ampliamente aceptado, concebido como un factor esencial para evitar obstáculos políticos a la hora de aprobar proyectos (Nelson, 1988), tanto que los montos cobrados se han incrementado en 70\% (Giménez, 2009).

La Ley de Urbanismo y Compensaciones de Inglaterra (Planning and Compensation Act, 1991), establece la responsabilidad al privado del cumplimiento de "planning obligations", las cuales son negociadas mediante convenios urbanísticos o asumidas de manera voluntaria aplicando la modalidad de "undertakings". En los Países Bajos, los municipios realizan un Plan de Urbanización que establece las inversiones en infraestructura y equipamiento público, las cuales luego son concretadas por los desarrolladores inmobiliarios mediante convenios con el municipio (Spatial Planning Act, 2008).

En Francia, los municipios implementan un Plan de Ocupación del Suelo que consigna la gestión y ejecución de las infraestructuras de urbanización. Estas se financian con una "tasa local de equipamiento", cuyo pago no está necesariamente vinculado al proyecto y se basa en el avalúo comercial de la construcción edificable actualizado anualmente (Code de l'urbanisme, 1967). Los aportes se establecen a nivel nacional, por superficie, y según el uso y tipo de la edificación. Además, se aplica una tasa por exceso de densidad (Code de l'urbanisme,1975), que permite a los municipios conceder un permiso con una constructibilidad mayor de la permitida, a cambio del pago de una tasa equivalente al valor de mercado del suelo.

En Latinoamérica, destacan los Certificados de Potencial Adicional de Construcción desarrollados en São Paulo (Brasil), mecanismo de subasta pública de metros adicionales de construcción (Smolka \& Furtado, 2014). El Plan Director Estratégico de Sáo Paulo limita el derecho de construcción a un coeficiente de "1", aunque la regulación admita un máximo superior. Para superar dicho coeficiente, los desarrolladores pagan una "Contrapartida Financiera" destinada al Fondo Municipal de Desarrollo Urbano. A medida que aumenta la edificabilidad del proyecto sobre el coeficiente básico, disminuye el costo del metro cuadrado de la contrapartida financiera. Basado en el Estatuto de la Ciudad, el Plan también contempla una Cuota de Solidaridad para todo proyecto con más de $20.000 \mathrm{~m}^{2}$, el cual debe pagar o donar un $10 \%$ de su superficie para vivienda social.

La Participación Municipal en las Plusvalías Urbanas de Colombia (Ley 388 de Desarrollo Territorial, 1997), consiste en un pago asociado al incremento del valor de la propiedad y efectuado por las propiedades localizadas en las zonas beneficiarias de acciones urbanísticas definidas en el Plan de Ordenamiento Territorial. La tas imputada a las plusvalías puede corresponder desde un 30\% a un 50\% del mayor valor del metro cuadrado. También destaca la Contribución Compensatoria en Rosario (Argentina), implementada en la década del 2000 gracias a "la audacia de la reformulación normativa que lo precedió” (Cuenya \& González, 2017, p. 80).

En Chile, las Zonas de Desarrollo Condicionado establecidas en el Plan Metropolitano de Santiago utilizan los pagos por impactos para que las nuevas urbanizaciones mitiguen o internalicen sus externalidades. La reciente Ley sobre Transparencia del Mercado del Suelo es considerada un avance, en tanto grava con un impuesto aquellos predios que, al ampliar el límite urbano, obtienen una ganancia de capital.

El principal debate asociado a estos mecanismos se centra en el destino de los aportes; esto es, si deben estar vinculados al proyecto que los origina o puede tener alcances mayores, en la perspectiva de bien común (Cámara de Diputados, Comisión de Vivienda, 2013). A modo de ejemplo, en el debate jurisprudencial en Colombia en torno al alcance de las cesiones urbanísticas obligatorias, estas fueron consideradas por un sector como expropiaciones sin indemnización que vulneran el derecho de propiedad (Pinilla, 2009).

\section{Preguntas de investigación y metodología}

Este trabajo se basa en la siguiente premisa: en ausencia de instrumentos de planificación que conduzcan a una densificación balanceada en áreas de creciente centralidad, la LAEP permite avanzar hacia un desarrollo más equilibrado de la ciudad consolidada, que no solo impone restricciones, sino que también involucra al privado en la construcción de la ciudad. La LAEP constituye, principalmente, un mecanismo de pago por impactos proporcionales a la densidad del edificio residencial. También es un mecanismo redistributivo, al obligar a reservar un $40 \%$ del aporte a un fondo intercomunal. En cierta medida, es un instrumento de captación de plusvalías, en tanto se basa en el avalúo del suelo para determinar el porcentaje de aporte en dinero.

Según el mecanismo de cálculo de los aportes al espacio público, estos no solo dependen de la densidad de ocupación, sino también del avalúo fiscal y la superficie predial. Proyectos con una misma densidad generan aportes muy diferentes. Cuando el aporte es en dinero, depende de atributos como la accesibilidad y la disponibilidad de equipamientos, los cuales se expresan en el avalúo fiscal. Cuando el aporte es en terreno, las características del espacio público cedido dependen, en gran medida, de la geometría del predio. De esta manera, la aplicación de la LAEP puede tender a reiterar inequidades en la distribución de bienes públicos urbanos, ya que comunas con mayores ingresos también tendrán mayor ganancia y dinamismo.

El principal objetivo de este trabajo es analizar el potencial impacto de la LAEP en barrios en renovación del AMs. Se enfoca en los aportes al espacio público que dicha ley exigirá a toda operación de densificación. Si bien la LAEP aplica a toda operación de densificación, este trabajo se enfoca en las operaciones de densificación residencial intensiva, en tanto esta forma de densificación constituye una de las principales tendencias de reestructuración espacial y transformación del AMs. 


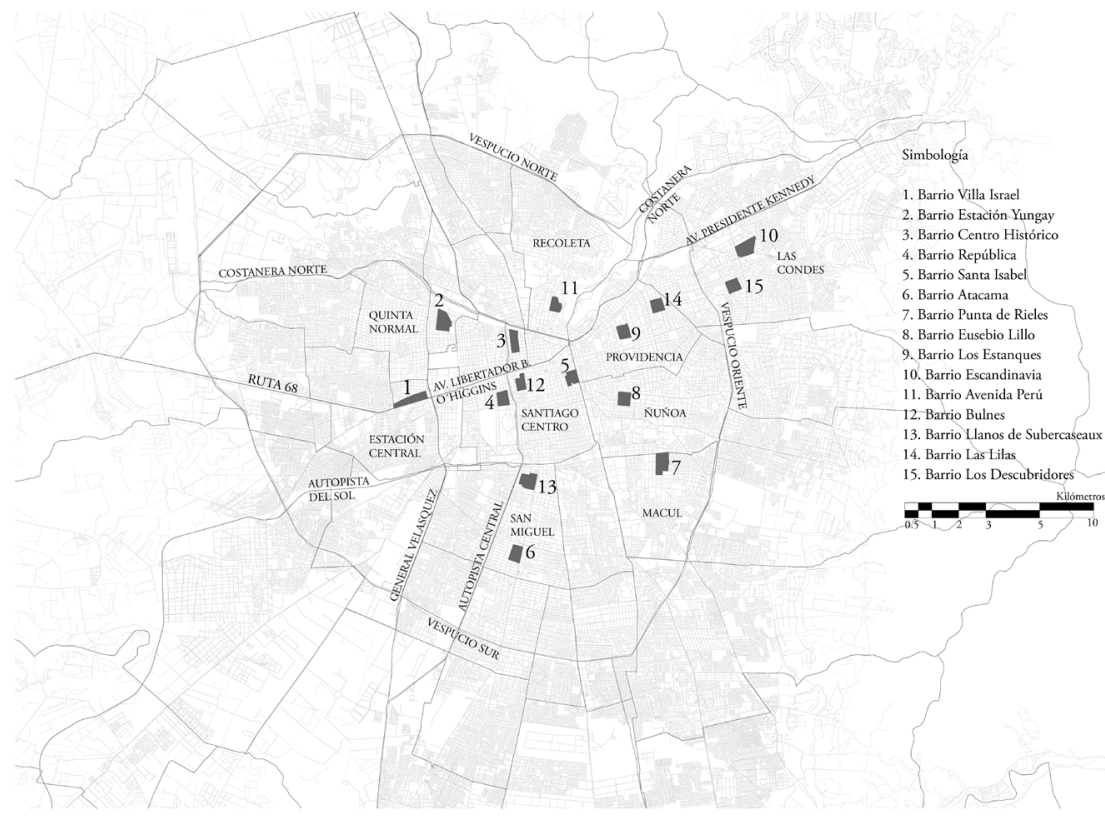

FIGURA I | Barrios de estudio en el AMs

FUENTE: ELABORACIÓN PROPIA

Específicamente, se busca: i) medir el potencial aporte al espacio público de proyectos de densificación intensiva en el AMs según lo establecido por la LAEP; ii) identificar su relación con distintas variables de la forma urbana, especialmente con las densidades de cada proyecto; y iii) discutir en qué medida la ley puede constituir un mecanismo que contribuya a reforzar la planificación urbana en Chile.

A continuación, se describe brevemente la metodología utilizada:

Selección de la muestra. El análisis se centró en áreas del AMs que se encuentran en proceso de renovación urbana. Se analizaron 415 proyectos en 15 barrios seleccionados de 25 hectáreas. La selección de barrios se basó en un cruce de densidades residenciales netas (viv/ha), zonas densificadas a partir de la década de 1990, actualización de planes reguladores comunales, grupos socioeconómicos predominantes y avalúo fiscal por manzana (tabla 2)

Con el objetivo de analizar las diferencias que se producen al traspasar un mismo porcentaje de aporte a su versión final en dinero y en suelo, se seleccionan seis edificios en los barrios Bulnes, República, Punta de Rieles, Eusebio Lillo, Los Descubridores y Estación Yungay (figura 4). Estos casos permiten analizar el impacto de la LAEP en términos cualitativos, para develar variables relevantes del edificio residencial en su entorno inmediato.

Levantamiento de datos. Los datos levantados para los 415 casos corresponden a: superficie útil $\left(\mathrm{m}^{2}\right)$, superficie predial $\left(\mathrm{m}^{2}\right)$ y número de viviendas, los cuales se obtienen de los permisos de edificación. La superficie útil corresponde a la suma de la superficie edificada de las unidades que conforman un edificio, calculada hasta el eje de los muros o líneas divisorias entre ellas y la superficie común.

Se simuló el aporte al espacio público de cada uno de los 415 edificios residenciales. Se calcularon los porcentajes de aporte al espacio público y los aportes en terreno y en dinero según el Reglamento de la LAEP, y las definiciones consignadas en la Ordenanza General de Urbanismo y Construcciones. Los aportes en dinero se calcularon utilizando el avalúo fiscal vigente de la superficie de aporte al espacio público, a partir de los valores de las Áreas Homogéneas del Servicio de Impuestos Internos (sII, 2018). Dicho valor se aumentó en función de los beneficios de mayor constructibilidad obtenidos por las operaciones de densificación, tales como el premio por fusión predial (30\% de aumento) o conjunto armónico $(50 \%$ de aumento) (artículo 182, LGUC)

A su vez, con el objetivo de comprender las distintas visiones que existen de la LAEP, se realizaron entrevistas a los siguientes informantes clave: jefe de la División de Desarrollo Urbano, Ministerio de Vivienda y Urbanismo (Minvu); abogado asesor de la División de Desarrollo Urbano del Minvu en el proceso de elaboración de la ley; asesora urbanista de la comuna de Santiago; arquitecto desarrollador de proyectos inmobiliarios; coordinador Área Vivienda y Urbanismo, Cámara Chilena de la Construcción; y académica experta en temas urbanos.

\section{Resultados}

a tabla 3 muestra los porcentajes de aporte al espacio público promedio de los edificios analizados por barrio y sus respectivas equivalencias en superficie y dinero. A partir de estos resultados, es posible comprobar tres cuestiones críticas, que se esarrollarán a continuación.

a) El porcentaje de aporte al espacio público de los edificios de densificación residencial equivale, en promedio, a un 75\% menos del tope exigido por ley

Se ha planteado que una vez que se implemente la LAEP, los aportes al espacio público serán bajos en relación con los bienes públicos urbanos requeridos por la densificación. Prácticamente todos los entrevistados seńalaron que la recaudación de los municipios será insuficiente para concretar los proyectos definidos en los planes comunales de inversiones. Sin embargo, hasta ahora no se ha dimensionado dicho déficit.

El porcentaje de aporte al espacio público promedio corresponde a 12,29\% (tabla 3). Los porcentajes promedio por barrio varían. El más alto lo ostenta Villa Israel (29,25\%), seguido por el Centro Histórico (27,35\%), Santa Isabel $(23,94 \%)$ y el barrio Bulnes $(23,42 \%)$. Los porcentajes más bajos se dan en los barrios Las Lilas (3,91\%), Los Estanques (4,94\%), El Llano (6,58\%), Eusebio Lillo (6,62\%) y Atacama (6,77\%)

$\mathrm{Al}$ analizar los aportes por edificio, se comprueba que un $40 \%$ de los casos realiza aportes al espacio público de entre 5,01\% y $10 \%$. Un 75\% de los casos, cuyas densidades alcanzan hasta los 2727 hab/ha, aporta al espacio público hasta un 15\%, esto es, casi dos tercios menos que el máximo establecido por ley (44\%) (tabla 4). 

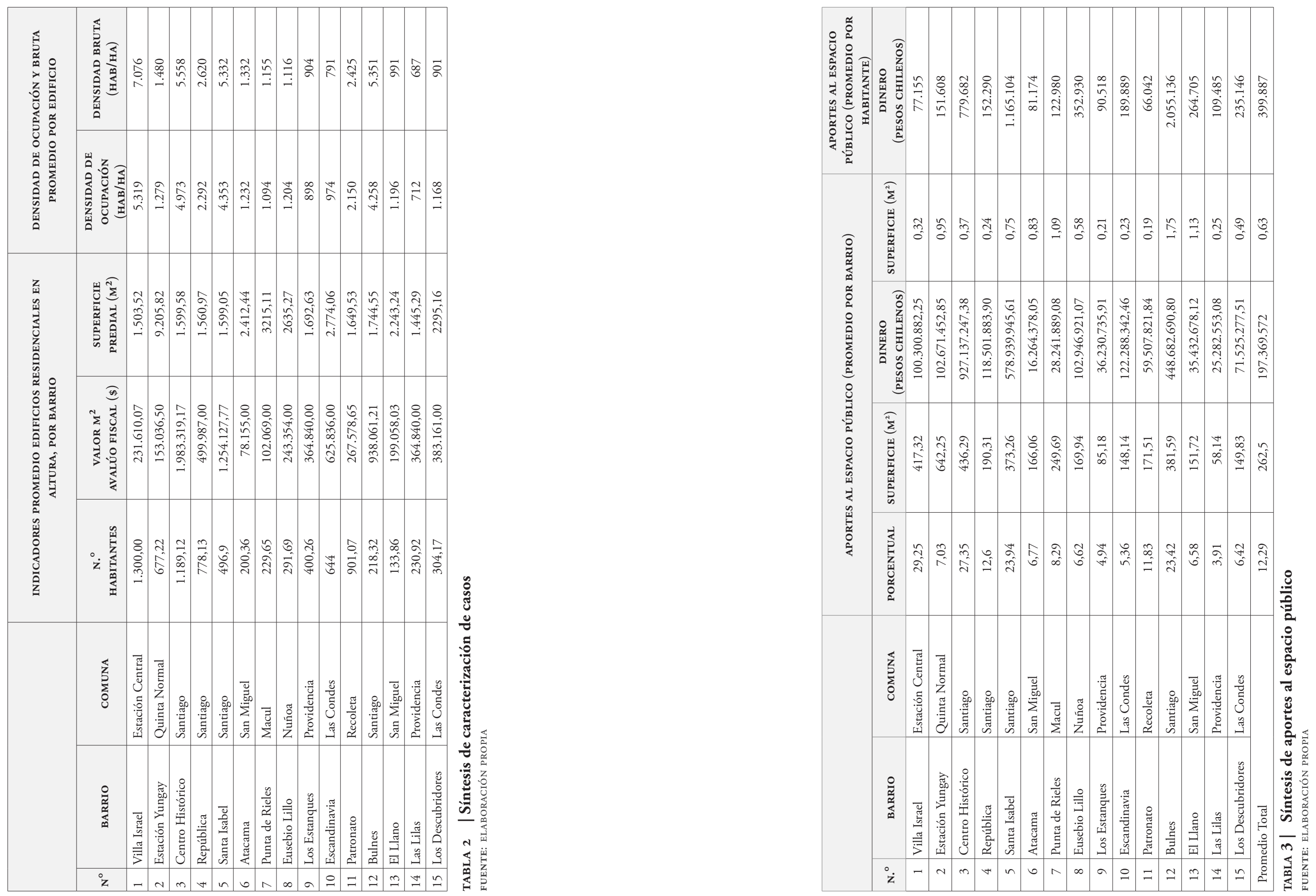


\begin{tabular}{|l|c|c|c|}
\hline $\begin{array}{c}\text { PORCENTAJE } \\
\text { DE APORTES AL } \\
\text { ESPACIO PÚBLICO }\end{array}$ & $\begin{array}{c}\mathbf{N}^{\mathbf{0}} \text { DE } \\
\text { CASOS }^{-}\end{array}$ & $\begin{array}{c}\text { PORCENTAJE } \\
\text { DE CASOS }\end{array}$ & $\begin{array}{c}\text { DENSIDAD DE OCUPACIÓN OBTENIDA } \\
\text { SEGÚN FÓRMULA DE CÁLCULO } \\
\text { DECRETO N }^{\circ} \mathbf{I} 4\end{array}$ \\
\hline $2,01-5$ & 102 & 24,58 & $365,28-909 \mathrm{hab} / \mathrm{ha}$ \\
\hline $5,01-10$ & 166 & 40,00 & $910-1.818 \mathrm{hab} / \mathrm{ha}$ \\
\hline $10,01-15$ & 44 & 10,60 & $1.819-2.727 \mathrm{hab} / \mathrm{ha}$ \\
\hline $15,01-20$ & 22 & 5,30 & $2.728-3.636 \mathrm{hab} / \mathrm{ha}$ \\
\hline $20,01-25$ & 38 & 9,16 & $3.637-4.545 \mathrm{hab} / \mathrm{ha}$ \\
\hline $25,01-30$ & 16 & 3,86 & $4.546-5.454 \mathrm{hab} / \mathrm{ha}$ \\
\hline $30,01-35$ & 16 & 3,86 & $5.455-6.363 \mathrm{hab} / \mathrm{ha}$ \\
\hline $35,01-40$ & 8 & 1,93 & $6.364-7.272 \mathrm{hab} / \mathrm{ha}$ \\
\hline $40,01-44$ & 1 & 0,24 & $7.273-8.000 \mathrm{hab} / \mathrm{ha}$ \\
\hline $44,00-56,57$ & 2 & 0,48 & $8.001 \mathrm{hab} / \mathrm{ha} \mathrm{en} \mathrm{adelante}$ \\
\hline Total & 415 & 100,00 & \\
\hline
\end{tabular}

TABLA 4 Porcentaje de aporte al espacio público en rangos y número de proyectos

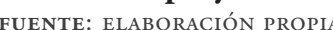

De esta manera, es posible plantear que el aporte máximo de $44 \%$ está sujeto a un límite de densidad (8000 hab/ha) excesivamente alto para el AMs, donde el promedio de densidad de ocupación por edificio residencial corresponde a 2057,72 hab/ha y las densidades más recurrentes fluctúan entre 1000 hab/ha y 2000 hab/ ha (figura 2). En efecto, el tope de 8000 hab/ha se ajusta a la densidad de ocupación de edificios destinados a equipamientos (S. Gysling, com. pers., 11/05/2018; P. Contrucci, com. pers., 11/06/2018; F. Errázuriz, com. pers., 19/04/2018; P. Álvarez, com. pers., 29/05/2018).

Solo en dos casos el aporte supera el tope de 44\%, con densidades de ocupación de 9676 hab/ha y 10.285 hab/ha. Estos edificios se localizan en la comuna de Estación Central, la cual no contaba con límites de altura ni densidad al momento de aprobarse dichos proyectos. Esto es relevante considerando las modificaciones reglamentarias (artículo 2/01/22, Ordenanza General de Urbanismo y Construcciones) y la tendencia de los municipios centrales y pericentrales a reducir densidades y alturas máximas (S. Gysling, com. pers., 11/05/2018).

El aumento de aporte es proporcional a la disminución de la densidad de tope de la fórmula. Si el tope de densidad para definir el $44 \%$ disminuyera, los aportes aumentarían significativamente. Con el máximo de $44 \%$ en una densidad de 6000 hab/ha, se recaudaría el doble de lo aportado con la actual fórmula. Con el máximo en una densidad de 4000 hab/ha el aporte sería tres veces mayor; y con el máximo en los $2000 \mathrm{hab} / \mathrm{ha}$ (más cercano a la realidad de los proyectos implementados en el AMs), el aporte sería cuatro veces mayor. Cabe señalar que el proyecto de ley fue planteado con una fórmula de cálculo que fijaba el límite de $44 \%$ de aporte en los $2000 \mathrm{hab} / \mathrm{ha}$ (equivalente al $11 \%$ de la fórmula actual).

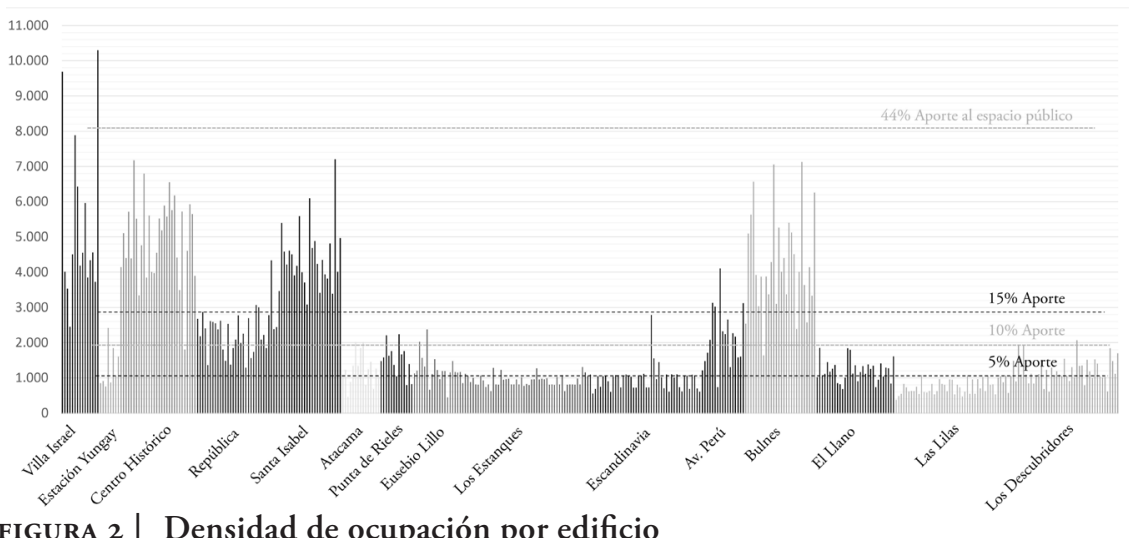

FIGURA 2 Densidad de ocupación por edificio

FUENTE: ELABORACIÓN PROPIA

Ahora bien, también es posible replantear que el máximo aporte corresponda al $44 \%$, parámetro que no necesariamente se condice con la realidad del crecimiento por densificación (E. Schlack, com. pers., 16/05/2018), y que más bien busca equiparar las exigencias realizadas a las urbanizaciones (E. Rajevic, com. pers., 9/05/2018).

b) El avalúo fiscal y la superficie del terreno tienen mayor incidencia en el aporte al espacio público que la densidad del edificio residencial

Un segundo punto crítico tiene relación con factores como el valor de suelo y la superficie predial, los cuales tienen mayor incidencia que la densidad en el aporte al espacio público. El porcentaje de aporte puede concretarse mediante un aporte en dinero a través de un pago a la municipalidad o mediante cesión gratuita de suelo. Una vez establecido el porcentaje, el aporte efectivo al espacio público incorpora dos variables: avalúo fiscal y superficie predial.

Aporte en dinero. Las diferencias en el avalúo fiscal de los barrios analizados son significativas (tabla 3). Responden a la localización específica del inmueble en relación con bienes públicos urbanos, por lo que la distribución del valor de suelo en los 415 casos es bastante heterogénea, con una desviación estándar de \$529.423. Mientras en el Centro Histórico el avalúo fiscal promedio de los edificios residenciales en altura corresponde a $\$ 2.698 .490 / \mathrm{m}^{2}$, en el barrio Atacama es 34 veces menor, correspondiendo apenas a $\$ 78.155 / \mathrm{m}^{2}$.

En términos de aporte en dinero, el promedio por edificio alcanza a $\$ 197.369 .572$ El aporte más alto, correspondiente a \$3.726.464.305, lo ostenta un edificio en el Centro Histórico, que cuenta con una alta densidad de ocupación (5570 hab/ha). El aporte en dinero más bajo, de $\$ 3.626 .888$, se da en el barrio Las Lilas, en un edificio con una densidad de ocupación baja (473,43 hab/ha).

El porcentaje de aporte en dinero al espacio público que realizan las torres residenciales en altura de un número significativo de casos, es bajo en relación con la cantidad de nuevos habitantes que llegan a residir a los barrios. En barrios con densidades altas y bajo avalúo fiscal, el aporte por cada nuevo residente puede ser 
tan bajo como $\$ 66.042, \$ 77.155$ o $\$ 81.174$ por persona (tabla 3 ). Tal es el caso de los barrios Avenida Perú, Villa Israel y Atacama. Si consideramos que un $60 \%$ de ese aporte queda en la comuna, se cuenta con apenas $\$ 39.625$, \$46.293 o $\$ 48.704$ por persona para inversión en mejoramiento e implementación de espacios públicos, valor que equivale a menos de $1 \mathrm{~m}^{2}$ de área verde (si consideramos un costo de $1 \mathrm{~m}^{2}$ de espacio público varía entre 1,5 y $\left.5 \mathrm{uF} / \mathrm{m}^{2}\right)$.

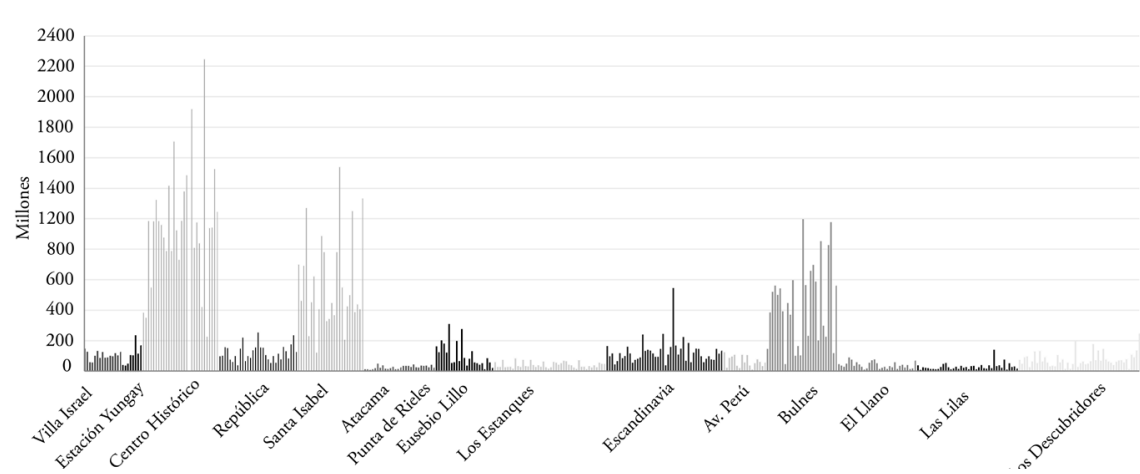

FIGURA 3 Monto en dinero de aporte por edificio (millones)

FUENTE: ELABORACIÓN PROPIA

Además, la LAEP permite que los aportes en dinero se materialicen en estudios, lo que puede ser crítico en comunas que presentan un déficit histórico de áreas verdes y espacios públicos (S. Gysling, com. pers., 11 mayo, 2018). Cabe destacar que un $70 \%$ del aporte al espacio público debe destinarse a movilidad, lo que puede constituir un detrimento a la inversión en áreas verdes, sobre todo considerando que los proyectos también deberán ejecutar obras de mitigación al impacto vial (F. Errázuriz, com. pers., 19/04/2018).

La correlación entre densidad y porcentaje de aporte es directa $(\mathrm{R} 2=1)$. También es significativa la correlación entre avalúo fiscal y aporte en dinero $(\mathrm{R} 2=0,7)$. Sin embargo, la correlación entre densidad y aporte en dinero no es tan fuerte a nivel barrial $(\mathrm{R} 2=0,40)$, lo que se explica por las variaciones en el avalúo fiscal. Es decir, el aporte en dinero no refleja necesariamente la densidad, sino más bien el avalúo fiscal del terreno donde se emplaza. Los edificios localizados en los barrios Punta de Rieles y Eusebio Lillo presentan densidades y porcentajes de aporte muy similares $(12,22 \%$ y $12,99 \%$ respectivamente) (figura 5$)$. Sin embargo, generan un aporte en dinero cuya diferencia es de casi diez veces. Cabe destacar la alta diferencia del avalúo fiscal en dos barrios con condiciones morfológicas relativamente similares. Esto es relevante, en tanto la LAEP se sustenta en el principio de proporcionalidad, bajo el cual el aporte es determinado por los habitantes que considera el edificio ( $y$ no el valor de suelo).

Si bien en zonas con alto avalúo el precio de las unidades cubre tanto un proyecto con unidades de calidad como buenos aportes para espacios públicos, en áreas con bajo avalúo un desarrollador puede optar por disminuir la calidad de las unidades con el fin de pagar aportes que puedan considerarse "onerosos" en ciertas zonas de la ciudad.
Los resultados señalados revelan lo complejo que resulta utilizar el avalúo fiscal como parámetro de cálculo del aporte al espacio público, considerando las significativas diferencias entre avalúo fiscal y comercial que presentan (F. Errázuriz, com. pers., 19/04/2018; P. Álvarez, com. pers., 29/05/2018), justamente, las áreas de menor centralidad. En efecto, en el año 2013, el 80\% de las transacciones de uso residencial en el AMs presentaba una diferencia del $60 \%$ entre avalúo fiscal y comercial (Eyzaguirre \& Razmilic, 2014).

Aporte mediante cesión gratuita de suelo. Aunque en menor medida que el valor de suelo, las superficies prediales de los edificios en altura también presentan una alta variabilidad. El promedio para los 415 casos corresponde a $2703 \mathrm{~m}^{2}$; y la desviación estándar, a $1540 \mathrm{~m}^{2}$. Se observa un rango de superficies desde $262,5 \mathrm{~m}^{2}$ hasta $11.567 \mathrm{~m}^{2}$ en edificios que presentan densidades de 7044 hab/ha y $748 \mathrm{hab} /$ ha (barrios Bulnes y Estación Yungay, respectivamente).

Las superficies prediales más bajas se localizan en las comunas de Estación Central, Providencia, Recoleta y Santiago. Las comunas con edificios residenciales con promedios de terrenos de mayor superficie corresponden a Quinta Normal $\left(9205 \mathrm{~m}^{2}\right)$ y Macul con $\left(3215 \mathrm{~m}^{2}\right)$.

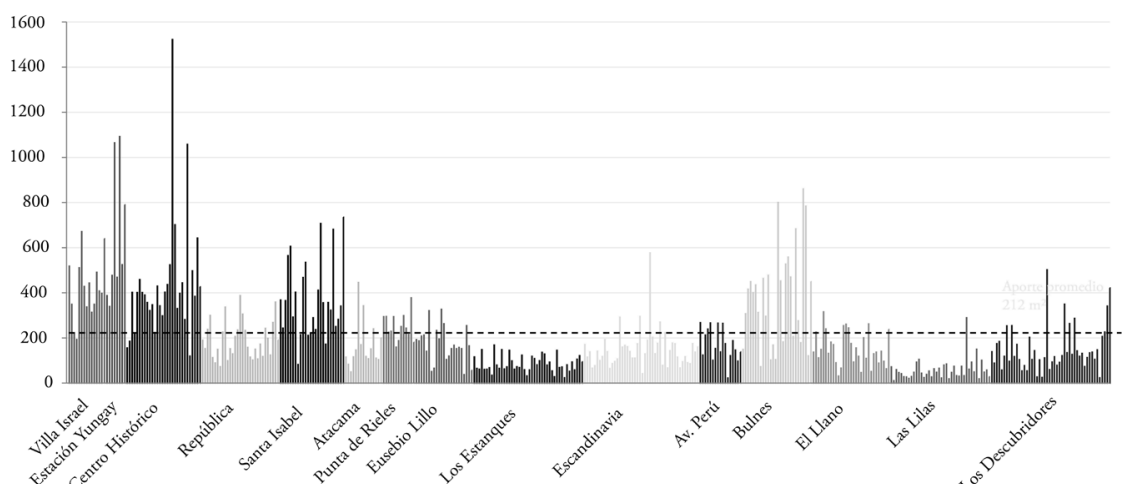

FIGURA 4 Superficie de aporte por edificio $(\mathrm{m} 2)$

FUENTE: ELABORACIÓN PROPIA

El promedio de aporte mediante cesión gratuita de suelo para toda la muestra corresponde a $212 \mathrm{~m}^{2}$. Esta superficie equivale a suponer que si un edificio con frente predial de 30 metros concretara su aporte mediante cesión de suelo, aportaría con aproximadamente 7 metros al ancho de la vereda.

Un 64\% de los 415 casos aporta una superficie inferior al promedio y un $28 \%$ aporta al espacio público menos de $100 \mathrm{~m}^{2}$. Los aportes más altos se concretarían principalmente en dos comunas: Quinta Normal y Santiago. En el barrio Estación Yungay, de origen industrial y desde hace una década en proceso de renovación, las superficies prediales superan los $8000 \mathrm{~m}^{2}$. También se observan cesiones de grandes terrenos en el Centro Histórico, casos que corresponden a la fusión de paños con superficie considerable (más de $3000 \mathrm{~m}^{2}$ ) y altas densidades de ocupación, lo que genera un aporte superior al 30\%. En ambos barrios, los aportes en suelo superarían os $1000 \mathrm{~m}^{2}$. 
Un 36\% de los casos aporta una superficie superior al promedio. No obstante, para la mayoría de los casos, la cesión de suelo es una alternativa poco factible de implementar, especialmente en barrios céntricos con una diversidad tipológica de predios, donde la normativa suele promover el agrupamiento continuo.

Aunque las cesiones de suelo constituyen una oportunidad, en la medida en que se cuenta con un proyecto urbano (E. Schlack, com. pers., 16/05/2018), la LAEP incentiva a que los aportes al espacio público se realicen en dinero y no en suelo (P. Álvarez, com. pers., 29/05/2018). Podría ocurrir que en casos con alto avalúo fiscal, el desarrollador opte por realizar el aporte en terreno. Aquí cabe el riesgo de que se cedan superficies residuales (F. Errázuriz, com. pers., 19/04/2018), cuyas dimensiones no contribuyan a mejorar el espacio público. Esto podría ocurri principalmente en aquellos edificios que ceden menos de $100 \mathrm{~m}^{2}$ en zonas con un alto valor de suelo, como es el caso del barrio Las Lilas.

Por otro lado, un mismo porcentaje de aporte se traduce en importantes diferencias de cesión de suelo cuando los paños presentan superficies disímiles (figura 5) En efecto, edificios con una misma densidad de ocupación pueden ser muy disímiles en términos de características volumétricas, como forma de agrupamiento, altura, ocupación de suelo, edificabilidad y distanciamientos, aspectos que inciden significativamente en su impacto en el espacio público (F. Errázuriz, com. pers. 19/04/2018). Dichas variables del edificio residencial no son consideradas en el cálculo del aporte al espacio público (figura 5).

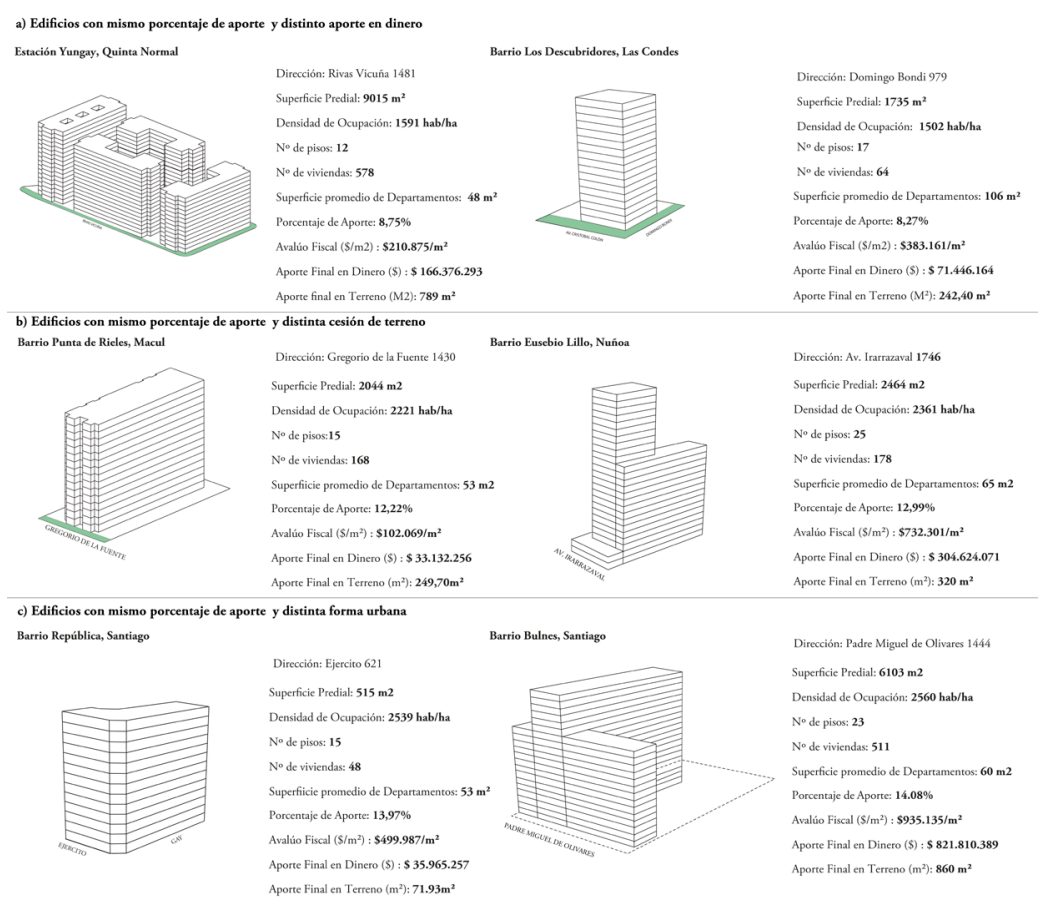

FIGURA 5 | Edificios con igual porcentaje de aporte y distinta cesión de terreno y forma urbana c) Al utilizar en la fórmula la densidad de ocupación y no la densidad bruta, se producen distorsiones respecto de la densidad planificada por los instrumentos de planificación territorial

La densidad de ocupación utilizada para definir el porcentaje de aporte al espacio público se calcula en función del número de habitantes según la superficie promedio de los departamentos de cada edificio (carga de ocupación) y no de la cantidad total de habitantes del edificio. Esta última forma de cálculo corresponde a la densidad bruta, parámetro utilizado tanto para definir el porcentaje de cesión gratuita de suelo en el crecimiento por extensión (Ordenanza General de Urbanismo y Construcciones, artículo 2.2.5), como para proyectar el crecimiento urbano en los instrumentos de planificación territorial.

Es decir, el mecanismo mediante el cual se establece el porcentaje de aporte al espacio público considera una densidad distinta de la que el instrumento de planificación proyecta para su crecimiento. Los aportes al espacio público asociados a los nuevos residentes en la comuna no necesariamente se encuentran ajustados al crecimiento poblacional estimado por el plan.

Esta diferencia se produce, en parte, porque la formula para calcular la densidad de ocupación no es lineal, sino que establece rangos de superficie de las unidades para estimar la carga de ocupación. Los rangos se traducen en "saltos" cuando el promedio de superficie de las unidades alcanza los $60 \mathrm{~m}^{2}$ y los $140 \mathrm{~m}^{2}$ (figura 6), los cuales constituyen una distorsión en la estimación de la densidad de ocupación y, por tanto, del porcentaje de aporte al espacio público. Así, dos edificios con una cantidad similar de unidades, que además se acercan al promedio de superficie de departamentos $\left(59 \mathrm{~m}^{2}\right.$ y $61 \mathrm{~m}^{2}$, o $139 \mathrm{~m}^{2}$ y $\left.141 \mathrm{~m}^{2}\right)$, pueden presentar diferencias de hasta 250 personas en su carga de ocupación. En este sentido, es posible que el mercado se incline por departamentos de $61 \mathrm{~m}^{2}$ (F. Errázuriz, com. pers., 19/04/2018).

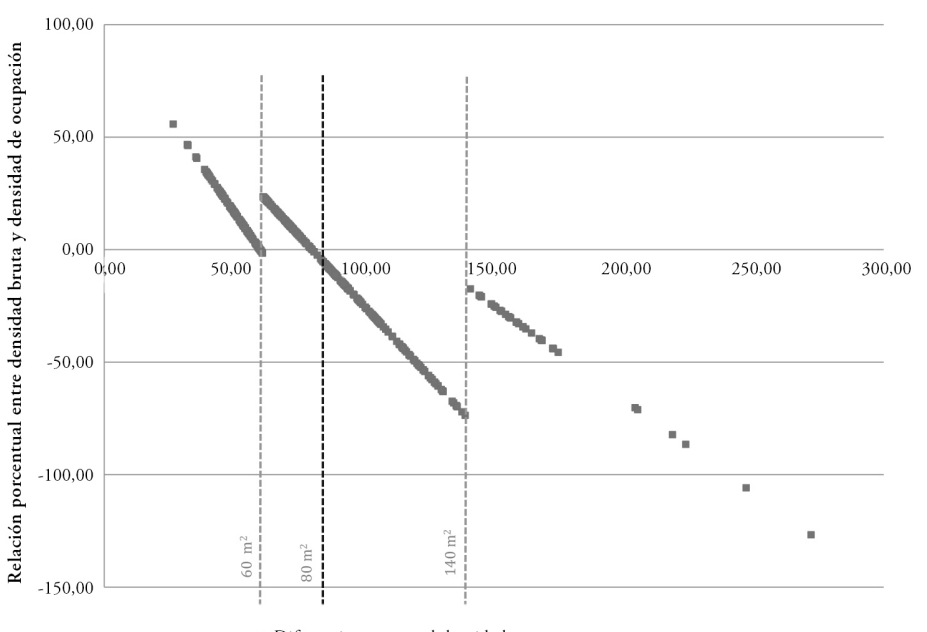

FIGURA 6 | Diferencia porcentual entre densidad bruta y densidad de ocupación y superficie de departamentos 
La densidad de ocupación coincide con la densidad bruta en aquellos edificios con una superficie promedio de los departamentos correspondiente a $60 \mathrm{~m}^{2}$ u $80 \mathrm{~m}^{2}$ (figura 6), los cuales equivalen a un $2,4 \%$ de los casos. Si la superficie promedio de las unidades es menor a $80 \mathrm{~m}^{2}$, la carga de ocupación es menor que si se hubiese calculado utilizando la densidad bruta. Un 53,6\% de los casos registra una densidad de ocupación menor que la densidad bruta. Se constatan casos en los cuales el porcentaje de aporte al espacio público es hasta un 30\% menor que el resultante del cálculo utilizando la densidad bruta.

Por el contrario, cuando la superficie promedio de las unidades es mayor a $80 \mathrm{~m}^{2}$, el aporte porcentual derivado de la densidad de ocupación es mayor al resultante con la densidad bruta ( $44 \%$ de los casos analizados). Tal es el caso de la comuna de Las Condes, donde la superficie promedio de las unidades supera los $100 \mathrm{~m}^{2}$. Al utilizar la densidad de ocupación se consideran entre cinco y siete habitantes por unidad, lo que aumenta el aporte en espacio público, a pesar de que la densidad bruta sea más baja o equivalente a otras comunas donde la densidad de ocupación es menor (como Providencia, por ejemplo).

Al margen de la discusión sobre cuál forma de cálculo de la densidad es la más apropiada, lo que aquí se busca relevar es que densidad de ocupación y densidad bruta pueden ser parámetros muy diferentes para estimar el número de habitantes por edificio y, en consecuencia, el porcentaje de aporte al espacio público asociado a dichos habitantes. Esto tiene implicancias relevantes, en tanto la LAEP busca que los edificios mitiguen el impacto que generan en relación con la cantidad de nuevos habitantes que se incorporan a un territorio. En los edificios con superficies promedio menores a $80 \mathrm{~m}^{2}$ (55\% de los casos analizados), se estaría realizando un aporte menor al correspondiente según la densidad bruta.

\section{Conclusiones}

La aprobación de la LAEP constituye un significativo avance para la gestión urbana en Chile y, según lo recabado en las entrevistas realizadas, es reconocida como tal por diversos actores, a pesar de sus limitaciones. Ahora bien, como se ha podido comprobar en este trabajo, para un cumplimiento de los objetivos de la ley se requerirá de importantes ajustes a los mecanismos que permitirán su implementación.

En primer lugar, es necesario ajustar la fórmula de cálculo del aporte en función de un tope de densidad razonable y acorde a la realidad de los procesos de densificación residencial del país. El tope de 8000 hab/ha no se ajusta a las densidades residenciales en altura del AMS y, por tanto, se traduce en un parámetro excesivamente permisivo. La laxitud del reglamento plantea una transgresión a la "razonabilidad técnica", la cual alude a una apropiada adecuación entre los objetivos postulados por la ley y las obligaciones que la norma impone, a través de un reglamento, para alcanzarlos (Cordero, 2008a).

Tal como lo establecía el proyecto de ley hasta su última etapa de tramitación, el Reglamento debiera contener fórmulas diferenciadas para usos comerciales y de servicios (para los cuales pareciera ser más pertinente el tope de 8000 hab/ha) y usos residenciales, poniendo el tope para estos últimos en los 2000 hab/ha. Este ajuste es modificable en el mediano plazo, e incrementaría hasta en cuatro veces los porcentajes de aporte al espacio público, constituyéndose así en un mecanismo factible para financiar el plan de inversiones en espacio público, especialmente de aquellas comunas más desfavorecidas.

En segundo lugar, la implementación de la ley debe avanzar en el cumplimiento del principio original de proporcionalidad con la densidad, especialmente en relación con los aportes en dinero. Este trabajo ha mostrado cómo las diferencias en el avalúo fiscal distorsionan dicho principio, promoviendo que las comunas con avalúos más altos obtengan una mayor recaudación de dinero por habitante. Esta distorsión se hace crítica en barrios con densidades muy altas y bajo avalúo fiscal. En estos casos, los esfuerzos debieran conducirse a que los aportes fueran en terreno, cuestión que presenta dos dificultades. Por un lado, estos barrios evidencian una subdivisión predial relativamente atomizada, con poca disponibilidad de suelo para cesión gratuita. Por otro, los municipios podrían incentivar a que los aportes se realicen en suelo y no en dinero, lo que requiere de un proceso de ajuste significativo al marco regulatorio existente. Otra forma de evitar una excesiva distorsión del principio de proporcionalidad es reemplazar el avalúo fiscal por el avalúo comercial de los terrenos.

En tercer lugar, los resultados aquí presentados relevan la importancia de contar oportunamente con Planes de Inversiones en Infraestructura y Espacio Público coherentemente articulados con otros instrumentos de planificación, como planes reguladores, planes maestros de transporte y de movilidad y planes de desarrollo comunal, entre otros. Esto plantea un desafío técnico y administrativo tanto para municipios como para futuros gobiernos regionales. Un factor crítico detectado consiste en la necesidad de contar con criterios uniformes de definición de densidades en los distintos mecanismos e instrumentos de gestión y planificación urbana. Por ejemplo, los planes reguladores comunales podrían tener la facultad de definir densidades en función de las superficies de los departamentos.

Mientras el Plan Intercomunal de Inversiones cumplirá un rol fundamental en la distribución de los aportes y la compensación de aquellas comunas con mayores déficits de espacio público e infraestructuras para la movilidad, el Plan Comunal es clave en la definición de proyectos de movilidad y espacio público ejecutados con los fondos recaudados, la definición de inversiones integradas a los barrios que proyectan crecimiento en altura y densidad, y la coordinación de los aportes en cesión de suelo.

Los procesos de densificación residencial implican importantes transformaciones en la calidad de vida de quienes residen, trabajan y visitan estos barrios. Así lo concibe la LAEP cuando plantea que no solo los recintos privados deben ser los adecuados, sino también los espacios públicos; y que contar con un espacio público de calidad es un requisito tanto frente a las casas, como a los departamentos, las oficinas o los centros comerciales. Se requiere avanzar hacia mecanismos efectivos de mitigación de impactos que aseguren procesos de densificación balanceados y de calidad, que cautelen la función social de la propiedad y promuevan el bien común. Estos desafíos implican avanzar hacia una mayor integración de planificación, regulación e inversión urbana, articulando una visión de ciudad, restricciones al dominio privado y la disposición de los medios para alcanzar dicha visión. 


\section{Agradecimientos}

Quisiéramos agradecer a la Comisión Nacional de Investigación Científica y Tecnológica (Conicyt), Proyecto Fondecyt 11170501; al Centro Nacional de Investigación para la Gestión Integrada de Desastres Naturales (Cigiden), Conicyt / Fondap / 15110017; y a la Comisión de Estudios Habitacionales y Urbanos del Ministerio de Vivienda y Urbanismo, por financiar este estudio.

\section{Referencia}

\section{Bibliografía}

Angel, S., Parent, J., Civco, D., \& Blei, A. (2011). Making room for a planet of cities (Policy Focus Report). Cambridge, MA: Lincoln Institute of Land Policy. https://www.lincolninst. edu/sites/default/files/pubfiles/making-room-for-a-planet-of-cities-full_0.pdf

Cabrera, J. (2008). El derecho de propiedad, la función social del suelo y la normativa urbana. Dimensiones (Cochabamba), 1, 120-134. http://hdl.handle.net/2268/95341

Cho, I., Trivic, Z., \& Nasution, I. (2017). New high-density intensified housing development in Asia: qualities, potential and challenges. Journal of Urban Design, 22(5), 613-636. https://doi.org/10.1080/13574809.2017.1311770

Clichevsky, N. (2001). La captación de plusvalias urbanas en la Argentina: futuro instrumento de equidad social? En M. Smolka \& F. Furtado (eds.), Recuperación de plusvalias en América Latina (pp. 1-36). Santiago de Chile: LOM, Colección Eurelibros.

Cordero, E. (2008a). El derecho urbanístico chileno y la garantía constitucional de la propiedad. Revista de Derechos Fundamentales, 2, 91-112. https://dialnet.unirioja.es servlet/articulo?codigo=3999271

Cordero, E. (2008b). De la propiedad a las propiedades. La evolución de la concepción libera de la propiedad. Revista de Derecho de la Pontificia Universidad Católica de Valparaíso. 31, 493-525. http://dx.doi.org/10.4067/S0718-68512008000200014

Cuenya, B. \& González, E. (2017). Planificación y redistribución de beneficios del desarrollo urbano: La contribución compensatoria en Rosario, Argentina. Revista INVI, 32(90), 77-104. http://revistainvi.uchile.cl/index.php/INVI/article/view/1061

De Mattos, C., Fuentes, L., \& Link, F. (2014). Tendencias recientes del crecimiento metropolitano en Santiago de Chile. ¿Hacia una nueva geografia urbana? Revista IN 29(81), 193-219. http://revistainvi.uchile.cl/index.php/INVI/article/view/837

Doménech, G. (2014). Las plusvalías urbanísticas en el derecho espańol. Un sistema de incentivos perversos. En M. Á. Jareño Leal (ed.), Corrupción pública: cuestiones de politica criminal (I, pp. 197-214). Madrid: Iustel. https://www.uv.es/gadopas/2014. plusvalias.urbanisticas

Echenique, M. (2006). El crecimiento y el desarrollo de las ciudades. En A. Galetovic (ed.), Santiago, ¿Dónde estamos y hacia dónde vamos? (Cap. 3: pp. 74-96). Santiago Chile: Centro de Estudios Públicos (СеP). https://www.cepchile.cl/cep/site/ docs/20170321/20170321161947/03 pdf
Ewing, R. \& Cervero, R. (2010). Travel and the built environment. Meta-analysis. Journal of the American Planning Association, 76(3), 265-294. https://doi.org/10. 1080/01944361003766766

Eyzaguirre, S. \& Razmilic, S. (2014, diciembre). Compra de colegios: Más difícil de lo que se cree. Puntos de Referencia, 389 (Edición online). Santiago, Chile: Centro de Estudio Públicos (CEP). https://www.cepchile.cl/cep/site/docs/20160304/20160304101019/ pder389_SEyzaguirre-y-SRazmilic.pdf

Fernández, A. \& Arpa, J. (2007). Density projects. 36 new concepts on collective housing. Vitoria Gasteiz, Álava, España: $a+t$ achitecture publishers.

Furtado, F (1997). Instrumentos para la recuperación de plusvalias en América Latina: Debilidad en la implementación, ambigüedad en la interpretación (Lincon Institute Research Report). Cambridge, MA: Lincoln Institute of Land Policy. https://www.lincolninst. edu/publications/working-papers/instrumentos-para-la-recuperacion-plusvalias-enamerica-latina

Gehl, J. (2010). Cities for people. Washington, DC: Island Press.

Giménez, P. (2009). Manejo de externalidades urbanas en Estados Unidos: la experiencia de Miami, Houston y San Diego (Documento de Trabajo 56, Cámara Chilena de la Construcción). http://biblioteca.cchc.cl/datafiles/21882.pdf

Healey, L. \& Mccormick, J. (1999). Urban revitalization and tax increment financing in Chicago. Goverment Finance Review (December 1999), 27-30. https://www. cdfa.net/cdfa/cdfaweb.nsf/ord/ac3442e8843ece3688257936005f0c13/\$file/ urbanrevitalizationandtifinchicago.pdf

Hidalgo, R. \& Arenas, F. (2009). Del país urbano al país metropolitano. Transformaciones recientes en las ciudades chilenas. En R. Hidalgo, C. de Matos, \& F. Arenas (eds.), Chile: del país urbano al país metropolitano (pp. 9-29). Santiago, Chile: Pontificia Universidad Católica de Chile. Serie GEOlibros, Colección EURE libros. http:// geografia.uc.cl/images/serie_GEOlibros/del_pais_urbano/arenas_hidalgo_Del_pais_ urbano_al_pais metropolitano.pdf

Hipólito de Oliveira, P. V., Hipólito de Oliveira, P. H., Farria de Mendes, W. L., Batista de Oliveira, M., \& Soraggi, M. V. (2015). Verticalização consciente: edificar integrando ao meio urbano. REINPEC-Revista Interdisciplinar Pensamento Cientifico, 1(1), 12-27. http://dx.doi.org/10.20951/2446-6778/v1n1a2

Krueckberg, D. (1995). The difficult character of property: To whom do things belong? Journal of the American Planning Association, 61(3), 301-309. https://doi. org/10.1080/01944369508975644

López Morales, E. \& Meza-Corvalán, D. (2015). Regulaciones públicas y explotación de rent de suelo: el boom inmobiliario de Nuñoa, Santiago, 2000-2010. Sociedad y Territorio, 15(48), 301-332. http://repositorio.uchile.cl/handle/2250/139567

Mancuso, F. (1980). Las experiencias del zoning. Barcelona: G. Gili.

Mullen, C., Duncan Associates. (2015). State Impact Fee Enabling Acts. http://impactfees.com/ publications\%20pdf/state_enabling_acts.pdf

Nelson, A. (2007). Development impact fees. Journal of the American Planning Association, 54(1), 3-6. https://doi.org/10.1080/01944368808977147 
Pinilla, J. (2009). Las Cesiones Urbanísticas Obligatorias en la jurisprudencia colombiana. Lecciones sobre su naturaleza y alcance. Memorias VIII Seminario ACIUR 2009 [Asociació Colombiana de Investigadores Urbano Regionales]. Instituto de Estudios Urbanos, Universidad Nacional de Colombia. http://www.institutodeestudiosurbanos.info/ descargasdocs/eventos/seminarios-de-investigacion-urbano-regional-aciur/memoriasviii-seminario-aciur-2009/mesas-tematicas/derecho-urbano/310-las-cesionesurbanisticas-obligatorias-en-la-jurisprudencia-colombiana-1

Pont, M. \& Haupt, P. (2009). Space, density and urban form. Rotterdam: Nai Publishers.

Rajevic, E. (2000). Derecho y legislación urbanística en Chile. Revista de Derecho Administrativo Económico, 2(2), 527-548. http://redae.uc.cl/index.php/redae/article/view/102

Razmilic, S. (2018). Exenciones a las contribuciones de bienes raíces. El Mercurio (2018, abril 27) | Opinión. https://www.cepchile.cl/exenciones-a-las-contribuciones-de-bienes-ra ces/cep/2018-04-30/155414.htm

Sánchez de Madariaga, I. (1997). Las aportaciones urbanísticas en la práctica norteamerican referencia a los casos británico y francés. Cuadernos de Investigación Urbanistica, $O(17)$ http://polired.upm.es/index.php/ciur/article/view/231

Sandroni, P. (2011). Recent experience with land value capture in São Paulo, Brazil. Land Lines, 23(3), 14-19. https://www.lincolninst.edu/publications/articles/recent-experienceland-value-capture-sao-paulo-brazil

Servicio de Impuestos Internos (sII), Chile. (2018). Planos de precios de terreno. Reavalúo 2018 [online]. http://www.sii.cl/destacados/reavaluo/2018/planos_precios.html

Sik Cho, I., Trivic, Z., \& Nasution, I. (2017). New high-density intensified housing developments in Asia: qualities, potential and challenges. Journal of Urban Design, 22(5), 613-636.

https://doi.org/10.1080/13574809.2017.1311770

Smolka, M. (2013). Implementación de la recuperación de plusvalias en América Latina: politicas e instrumentos para el desarrollo urbano. Cambridge, MA: Lincoln Institute of Land Policy.

Smolka, M. \& Amborski, D. (2003). Recuperación de plusvalías para el desarrollo urbano: una comparación inter-americana. EURE, 29(88), 55-77. http://dx.doi.org/10.4067/ S0250-71612003008800003

Smolka, M. \& Furtado, F. (2001). Recuperación de plusvalias en América Latina. Santiago, Chile: LOM, Colección Eurelibros.

Smolka, M. \& Furtado, F. (eds.). (2014). Instrumentos notables de politicas de suelo en América Latina. Ecuador: Lincoln Institute of Land Policy / Ministério das Cidades, Brasil Banco del Ecuador. https://www.lincolninst.edu/sites/default/files/pubfiles/instrumen tos-notables-politicas-de-suelo-america-latina-full_0.pdf

Vicuńa, M. (2017). Impacto de la densificación residencial intensiva en la segmentación del tejido urbano de Santiago: un enfoque cuantitativo. Revista 180, n. ${ }^{\circ} 40$, 78-93. http:// dx.doi.org/10.32995/rev180.Num-40.(2017).art-399

\section{Leyes y reglamentos}

Cámara de Diputados, Comisión de Vivienda (2013, enero 9). Sesión 129. Legislatura 360: "Informe de la Comisión de Vivienda y Desarrollo Urbano recaído en el proyecto de ley que modifica la Ley General de Urbanismo y Construcciones y leyes complementarias para establecer un sistema de aportes al espacio público aplicable a los proyectos de construcción". Boletín 8493-14. https://www.camara.cl/pdf. aspx?prmID=8429\&prmTIPO=INFORMECOMISION

Ley N. ${ }^{\circ} 388$ de Desarrollo Territorial, Colombia. Diario Oficial de Colombia 43.091. Colombia (1997, julio 18). http://recursos.ccb.org.co/ccb/pot/PC/files/ley388.html

Ley N. 20.958 que establece un sistema de aportes al espacio público. Diario Oficial de la República de Chile. Santiago, Chile (2016, octubre 15). http://bcn.cl/1xz2k

Mensaje Presidencial a la Cámara de Diputados 90-360 (2012, agosto 3). Reproducido en Biblioteca del Congreso Nacional de Chile, "Mensaje de S.E. el Presidente de la República con el que se inicia un proyecto de ley que modifica la Ley General de Urbanismo y Construcciones y leyes complementarias para establecer un sistema de aportes al espacio público aplicable a los proyectos de construcción". https://www.bcn. cl/historiadelaley/nc/historia-de-la-ley/vista-expandida/5635/\#h2_1_1

Planning Act 2008, Chapter 29. Inglaterra (2008, noviembre 26). https://www.legislation.gov. uk/ukpga/2008/29/pdfs/ukpga_20080029_en.pdf

Planning and Compensation Act 1991, Chapter 34. Section 12. Inglaterra (1991, julio 25). http://www.legislation.gov.uk/ukpga/1991/34/section/12

\section{Entrevista}

P. Álvarez. Coordinador Área Vivienda y Urbanismo, Cámara Chilena de la Construcción.

P. Contrucci. Jefe de la División de Desarrollo Urbano, Ministerio de Vivienda y Urbanismo (MINVU).

F. Errázuriz. Arquitecto desarrollador de proyectos inmobiliarios.

S. Gysling. Asesora urbanista de la comuna de Santiago.

E. Rajevic. Abogado asesor de la División de Desarrollo Urbano, Ministerio de Vivienda y Urbanismo (MINVU)

E. Schlack. Arquitecta urbanista y académica experta en temas urbanos. 